\title{
Factors influencing the value of daylight factor
}

\author{
Petra Nováková ${ }^{1, *}$, and František Vajkay ${ }^{1}$ \\ ${ }^{1}$ University of Technology in Brno, Faculty of Civil Engineering, 602 00, Brno, Czech Republic
}

\begin{abstract}
Daylight has been used for centuries as the main source of light in the interior and has always been an implicit part of architecture since the buildings existed. Not only does it replace electrical lighting during the day, reducing electric power consumption, but it also affects heating and cooling, making it an important parameter in energy efficient design. Research has shown that daylight is a great asset to health and comfort, so it is crucial for building occupants. Daylighting of the interior spaces of buildings and their functionally defined parts is proposed according to visual activities. The minimum values for daylight factor are set for individual visual activities. This article deals with factors influencing the value of the daylight factor.
\end{abstract}

\section{Introduction}

Daylight has been used for centuries as the main source of light in the interior and has always been an implicit part of architecture since the buildings existed. Daylight not only replacing electrical lighting during the day, reducing energy consumption, but it also affects heating and cooling. For this reason, it is an important parameter in the energy-efficient design of buildings. Recent research has also shown that daylight is a great asset to health and comfort and it is crucial for building occupants.

Daylight is an irreplaceable factor in the environment and it is a prerequisite for the healthy use of the indoor environment of buildings. Ensuring daylight access to the interior is the task of building design. The aim is to provide a sufficient amount of daylight for the visual work that users of indoor buildings perform.

The so-called daylight factor D [\%] is a quantitative criterion for the assessment of illuminance daylight [6]. It is the ratio of the illumination at the point of the plane E [lx] by the direct and reflected skylight at the time and the simultaneous illumination of the outdoor $\mathrm{E}_{\mathrm{H}}[\mathrm{lx}]$ of the uncluttered horizontal plane in a cloudy sky based on the International Commission on Illumination (CIE) standard [4].

$$
D=\left(E / E_{H}\right) 100 \%
$$

The daylight factor consists of three components: the sky component Ds [\%], the externally reflected component De [\%] and the internally reflected component Di [\%]. In the calculation, each component is determined separately and the final value of the daylighting factor is obtained as the sum of all three components according to the formula:

\footnotetext{
*Corresponding author: petran.3011@gmail.com
} 


$$
D=D s+D e+D i
$$

The value of $\mathrm{D}$ depends on building types, window sizes, frames and position, types of glazing, transmission characteristics of glazing, cleanliness of glazing, and interior room surface reflectance [5]. This contribution deals with factors affecting the value of the daylight factor with the focus on the factors of pollution and light transmittance by window glazing.

\section{Parameters influencing daylight factor}

When the light passes through the illuminating opening, the value of the luminous flux decreases depending on the glazing material, due to the opaque parts of the window structure and the glazing contamination. Further light loss can occur by shielding the structures under consideration of the building or other permanently installed interior equipment.

The reduction of the luminous flux is characterized by the light transmittance factor $\tau$ [], which is defined as the ratio of the passing light flux $\Phi_{\mathrm{t}}[\mathrm{lm}]$ to the incident light flux $\Phi_{0}$ [lm]. [3]

$$
\tau=\Phi_{\mathrm{t}} / \Phi_{0}
$$

The luminance factor shading obstacles $k[-]$ expresses the lighting technical characteristics of the shielding obstacles. It is defined as the ratio of luminance $L_{\mathrm{p}}\left[\mathrm{cd} \cdot \mathrm{m}^{-2}\right]$ of the shadow obstacle to $L_{(\varepsilon)}\left[\mathrm{cd} \cdot \mathrm{m}^{-2}\right]$ of the sky that the obstacle covers. [3]

$$
k=L_{p} / L_{(\varepsilon)}
$$

The light reflection factor $\rho[-]$ is the property of the body surface. It is determined as the ratio of the reflected light flux $\Phi_{\mathrm{r}}[\mathrm{lm}]$ to the incident light flux $\Phi_{0}[\mathrm{~lm}]$. [3]

$$
\rho=\Phi_{r} / \Phi_{0}
$$

The light reflection factor is related to the color of the surface and it ranges from 0 to 1 for completely absorbent (black) to fully reflective (white) surfaces. In the calculation, the factors of the individual faces (ceiling, walls and floors of the room being considered) or the mean value of this factor are determined. [3]

The light transmittance $\tau[-]$ is characterized by a reduction in the luminous flux and is defined as the ratio of the passing light flux $\Phi_{\mathrm{t}}[\mathrm{lm}]$ to the incident light flux $\Phi_{0}[\mathrm{~lm}]$. [3]

$$
\tau=\Phi_{\mathrm{t}} / \Phi_{0}
$$

Directional transmittance factor $\tau_{\psi}[-]$ is the variable influencing the light transmission depending on the direction of light passing through the glazing. The light transmission factors in the normal direction $\tau_{s, n o r}[-]$ is defined if the light flux is perpendicular to the plane of the glazing. In the case of multiple glazing, the final factor is determined as the multiple of partial factors. Sometimes it is reported by the glass manufacturer. [3]

Light transmittance factor due to shielding by opaque of the illumination opening $\tau_{k}[-]$, for example, window frames, transoms, is expressed as the proportion of the translucent area $S_{\mathrm{s}}\left[\mathrm{m}^{2}\right]$ and the total area $\left[\mathrm{m}^{2}\right]$ of the illumination opening. [3]

$$
\tau_{k}=\mathrm{S}_{s} / \mathrm{S}_{c}
$$


This factor greatly simplifies calculations with a relatively low loss of accuracy. It allows the calculation only with the dimensional dimensions of the illumination openings. [3]

The light transmission factor due to the lighting control device $\tau_{r}[-]$ has a similar character as the light transmittance due to shading by the opaque illumination structures. [3]

$$
\tau_{r}=\left(\mathrm{S}_{s}-\mathrm{S}_{r}\right) / \mathrm{S}_{s}
$$

The pollution factor $\tau_{z}[-]$ expresses losses due to glazing contamination. The values are given in Table 1. The final pollution factor is obtained by the multiple of the partial pollution factors from the outside $\tau_{z e}[-]$ and inside $\tau_{z i}[-]$. [3]

$$
\tau_{z}=\tau_{\mathrm{ze}} \tau_{\mathrm{zi}}
$$

Table 1. The pollution factors [1].

\begin{tabular}{|c|c|c|c|c|}
\hline \multirow{2}{*}{$\begin{array}{c}\text { Type of } \\
\text { illumination } \\
\text { opening }\end{array}$} & $\begin{array}{c}\text { Angle of the } \\
\text { illuminating } \\
\text { opening glazing }\end{array}$ & \multirow{2}{*}{$\begin{array}{c}\text { Air } \\
\text { pollution }\end{array}$} & $\begin{array}{c}\text { Po the outside } \\
\tau_{\mathrm{ze}}(-)\end{array}$ & $\begin{array}{c}\text { on the inside } \\
\tau_{\mathrm{zi}}(-)\end{array}$ \\
\hline \multirow{3}{*}{ vertical } & \multirow{3}{*}{$90^{\circ}$} & small & 0.95 & 0.95 \\
\cline { 3 - 5 } & & medium & 0.90 & 0.85 \\
\cline { 3 - 5 } & & large & 0.85 & 0.65 \\
\hline \multirow{3}{*}{ oblique } & \multirow{3}{*}{$45^{\circ}$} & small & 0.80 & 0.95 \\
\cline { 3 - 5 } & & medium & 0.70 & 0.90 \\
\cline { 3 - 5 } & & large & 0.60 & 0.80 \\
\hline \multirow{3}{*}{ horizontal } & \multirow{2}{*}{$0^{\circ}$} & small & 0.70 & 0.95 \\
\cline { 3 - 5 } & & medium & 0.60 & 0.90 \\
\cline { 3 - 5 } & & large & 0.50 & 0.80 \\
\hline
\end{tabular}

The light transmission factor due to the shielding of the building structure $\tau_{b}[-]$ buildings is mainly used in high-rise buildings with indoor lighting (planks and trusses). [3]

The light transmittance factor $\tau_{0, \psi}[-]$ is determined according to the formula:

$$
\tau_{0, \psi}=\tau_{\mathrm{s}, \psi} \tau_{\mathrm{k}} \tau_{\mathrm{r}} \tau_{\mathrm{z}} \tau_{\mathrm{b}}
$$

The cumulative light transmission factor in the direction of normal $\tau_{0, \text { nor }}[-]$ is determined according to the formula:

$$
\tau_{0, \text { nor }}=\tau_{\mathrm{s}} \tau_{\mathrm{k}} \tau_{\mathrm{r}} \tau_{\mathrm{z}} \tau_{\mathrm{b}}=\tau_{0, \psi} / \tau_{\mathrm{b}}
$$

\section{Measurement of light transmission of glazing depending on pollution}

Air pollution is small in the case of fall of the dust of up to $50 \mathrm{Mg} \cdot \mathrm{km}^{-2} \cdot \mathrm{year}^{-1}$ and high if the case of fall of dust over $200 \mathrm{Mg} \cdot \mathrm{km}^{-2} \cdot \mathrm{year}^{-1}$. Indoor air pollution is considered to be moderate in clean workshops, warehouses, etc. Conversely, large pollution is typical of areas with significant sources of dust in the interior such as dust workshops. [3] 
Table 2. Mean values of light transmission of windows [\%].

\begin{tabular}{|c|c|c|c|}
\hline Location & Window & Month in 2018 & Transmittance [\%] \\
\hline \multirow{12}{*}{$\begin{array}{c}\text { České } \\
\text { Budějovice }\end{array}$} & \multirow{6}{*}{$\begin{array}{l}\text { Window in the kitchen } \\
\text { (4NP), south facing, } \\
\text { street, behind window of } \\
\text { flower }\end{array}$} & January & 92.3 \\
\hline & & February & 90.9 \\
\hline & & March & 89.8 \\
\hline & & April & 88.9 \\
\hline & & May & 86.3 \\
\hline & & June & 85.6 \\
\hline & \multirow{6}{*}{$\begin{array}{l}\text { Window in the bedroom } \\
\text { (4NP), facing north, into } \\
\text { the garden }\end{array}$} & January & 93.1 \\
\hline & & February & 93.0 \\
\hline & & March & 92.2 \\
\hline & & April & 91.7 \\
\hline & & May & 89.8 \\
\hline & & June & 88.9 \\
\hline \multirow{24}{*}{$\begin{array}{l}\text { Hluboká } \\
\text { nad } \\
\text { Vltavou }\end{array}$} & \multirow{6}{*}{$\begin{array}{l}\text { Window in the children's } \\
\text { room ( } 2 \mathrm{NP}) \text {, facing } \\
\text { west, into the street }\end{array}$} & January & 87.2 \\
\hline & & February & 86.6 \\
\hline & & March & 85.9 \\
\hline & & April & 85.2 \\
\hline & & May & 84.1 \\
\hline & & June & 83.2 \\
\hline & \multirow{6}{*}{$\begin{array}{c}\text { Window in the children's } \\
\text { room (2NP), east facing, } \\
\text { garden }\end{array}$} & January & 87.4 \\
\hline & & February & 86.9 \\
\hline & & March & 86.5 \\
\hline & & April & 86.0 \\
\hline & & May & 85.1 \\
\hline & & June & 84.4 \\
\hline & \multirow{6}{*}{$\begin{array}{l}\text { Window in the living } \\
\text { room ( } 2 \mathrm{NP}) \text {, facing east, } \\
\text { into the street }\end{array}$} & January & 86.7 \\
\hline & & February & 86.1 \\
\hline & & March & 85.5 \\
\hline & & April & 84.9 \\
\hline & & May & 83.3 \\
\hline & & June & 82.5 \\
\hline & \multirow{6}{*}{$\begin{array}{l}\text { Window in the bathroom } \\
\text { (2NP), facing west, } \\
\text { street, sunroof }\end{array}$} & January & 79.2 \\
\hline & & February & 79.0 \\
\hline & & March & 78.2 \\
\hline & & April & 77.6 \\
\hline & & May & 76.3 \\
\hline & & June & 75.7 \\
\hline
\end{tabular}

Measurement of the light transmission of window glazing took place in six places in the Czech Republic for half a year. The first location was in the center of the regional town of České Budějovice and the second location was on the outskirts of Hluboká nad Vltavou always on several different windows with the different orientation.

The windows were washed before the first measurement, and then the values of light transmission of window glazing were measured once a week. The measured values have changed over time depending on the contamination of the glazing surfaces. The mean values of light transmittance for each month are shown in Table 2.

From the measured values is evident that the contamination by half year not-washing window affects the light transmission of window glazing in the range of several percent. 
The highest value was $6.7 \%$. Different results of individual windows occurred due to the different locations, where the ductility of the regional city is also dustier due to the different location, orientation and depending on the glazing material.

\section{Conclusion}

Daylight is one of the most important environmental factors. Most building users evaluate the quality of the indoor environment based on subjective feelings, including lighting, and they are not interested, for example, moments in construction, and they take it for granted that the building is stable. This is evidenced by the offers of real estate such as sunny, bright, airy apartment with south orientation and the like.

The indoor environment of buildings is one of the basic parameters that affect people's health. The indoor environment is the second significant parameter after the lifestyle of the population. People are adapted and dependent on the daylight due to the development of life on our planet for several million years in the daylight and its changes throughout the day and year. Daylight can't be replaced by artificial sources and, together with direct sunlight, is a necessary part of our environment as well as air, water, Earth gravity and the like. Man is temporarily able to endure considerable inconvenience. Long-term lack of daylight has a negative impact on the health of people occupying an inconvenient building.

Daylight is a renewable resource. The sun shines, heats and heals for free. It is necessary to think about it during the process of building design. The urban design of the area, the design of the proportions of the interior spaces of the buildings, the choice of size and the location of the lighting openings are determinative factors. It is also necessary to take into account the factors influencing the value of the luminous flux passing through the illuminating opening into the interior, such as the choice of glazing material, glazing, shielding, and the like.

Measurement of window light transmissions during the six-month period without washing proves that the pollution significantly affects the final value of the luminous flux flowing into the interior. The greatest difference in light transmission was $6.7 \%$ after half a year of no-washing. Location, orientation, positioning and glazing material have an effect on the final contaminant of a particular window.

This paper has been worked out under the project No. LO1408 "AdMaS UP - Advanced Materials, Structures and Technologies", supported by Ministry of Education, Youth and Sports under the „National Sustainability Programme I" and under the project No. FAST-S-18-5536 supported by Grant Agency of Brno University of Technology.

\section{References}

1. ČSN 73 0580-1 Daylighting of buildings - basic requirements (2007)

2. M. Halyhaja, Building thermal technology lighting and acoustics (Alfa, Bratislava, 1985)

3. J. Kaňka, Light, 2008/3, 7 (2008)

4. CIE Home Page, Available on http://www.cie.co.at/publications/cie-standard-overcastsky-and-clear-sky (2018)

5. Lighting Control and Daylight Use (H.M. Stationery Office: London, UK, 1983)

6. S.-J. Jung, S.-H. Yoon, Energies, 11(7), 6 (2018) 